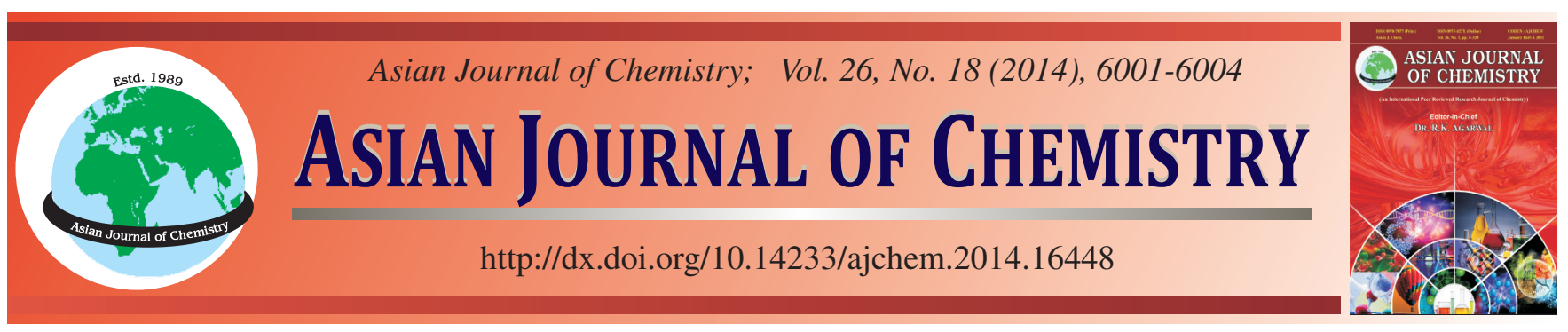

\title{
Design and Synthesis of Three Naphthol Derivatives Using Several Strategies
}

\section{Lauro Figueroa-Valverde ${ }^{1, *}$, Francisco Díaz-Cedillo ${ }^{2}$, Marcela Rosas-Nexticapa $^{3}$, Elodia García-Cervera ${ }^{1}$, Eduardo Pool-Gómez ${ }^{1}$ and Maria López-Ramos ${ }^{1}$}

\begin{abstract}
${ }^{1}$ Laboratory of Pharmaco-Chemistry, Faculty of Chemical Biological Sciences, University Autonomous of Campeche, Av. Agustín Melgar s/n, Col Buenavista C.P. 24039 Campeche Cam., México

${ }^{2}$ Escuela Nacional de Ciencias Biológicas del Instituto Politécnico Nacional. Prol. Carpio y Plan de Ayala s/n Col. Santo Tomas, México, D.F. C.P. 11340 , Mexico

${ }^{3}$ Facultad de Nutrición, Universidad Veracruzana, Médicos y Odontologos s/n C.P. 91010, Unidad del Bosque Xalapa Veracruz, México
\end{abstract}

*Corresponding author: Tel: +52 9818119800, Ext: 3070105; E-mail: lauro_1999@yahoo.com

Received: 30 September 2013; $\quad$ Accepted: 13 January 2014; $\quad$ Published online: 1 September 2014; $\quad$ AJC-15841

\begin{abstract}
In this study, three naphthol derivatives were synthesized. The first stage, involved preparation of 3-[[2-(3-hydroxy-13-methyl6,7,8,9,11,12,13,14,15,16-decahydro-cyclo- penta[a]phenanthren-17-ylideneamino)-ethylamino]-(3-hydroxy-naphtalen-2-yl)-methyl]-1,7,7trimethyl-bicyclo[2.2.1] heptan-2-one (4) by the reaction of 1,7,7-trimethyl-bicyclo[2.2.1]heptan-2-one (1) with 17-(2-amino-ethylimino)13-methyl-7,8,9,11,12,13,14,15,16,17-decahydro-6H-cyclopenta[a]phenanthren-3-ol (2) and 2-hydroxy-1-naphthaldehyde (3) using proline as catalyst. The second stage was achieved by the reaction of compund $\mathbf{1}$ with 1-[(2-amino-ethylamino)-phenyl-methyl]-naphthalen-2-ol to form the compound 1-\{phenyl-[2-(1,7,7-trimethyl-bicyclo[2.2.1]hept-2-ylideneamino)ethyl-amino]-methyl\}naphtalen-2-ol (6) using boric acid as catalyst. The third stage was achieved by the synthesis of N-[3-(1-hydroxy-10a,12a-dimethyl-2,2,3a,3b,4,5,10,10a,10b,11,12,12adodecahydro-1H-7-oxa-8-azadicyclopenta[a,h]phenanthren-1-ylethynylamino)-3-(3-hydroxy-naphtalen-2-yl)-propyl]-succinamic acid 3-allyl5-methoxy-phenylester (9) using the three components system (2-hydroxy-1-naphthaldehyde, 4-allyl-2-methoxyphenyl 4-[(2aminoethyl)amino]-4-oxobutanoate anddanazol). The structure of all compounds obtained was confirmed by elemental analysis, spectroscopy and spectrometry data.
\end{abstract}

Keywords: Naphthol derivative, Boric acid, Proline.

\section{INTRODUCTION}

There are several methods reported for synthesis of naphthol derivatives; for example, the synthesis of 4-isopropoxynaphthalene-1-carbaldehyde by the reaction of isopropyl $o$-ethynyl benzoate with butyl vinyl ether using $\mathrm{PtCl}_{2}$ as catalyst ${ }^{1}$. Other reports indicate the tandem pummerer Diels-Alder sequence for the preparation of $\alpha$-thiosubstituted naphthalene derivatives $^{2}$. Additionally, other studies ${ }^{3}$ showed the synthesis of 1carbamato-alkyl-2-naphthol derivatives via a three-component condensation reaction between aryl aldehydes, 2-naphthol and carbamates in the presence of $\mathrm{SiO}_{2}-\mathrm{NaHSO}_{4}$ as a heterogeneous catalyst under thermal and solvent-free conditions ${ }^{3}$. Other reports indicate the synthesis of 1,8-diphenylnaphtalene and 1-iodo-8-phenylnaphtalene by the reaction of lithium diphenyl cuprate and aryl halides ${ }^{4}$. Also, there are studies ${ }^{5}$ which shown the development of (S)-1-(3-hydroxy-2-naphthylcarbonyl)pyrrolidine-2-carboxylic acid methyl ester by the reaction of 3-hydroxy-2-naphthoic acid and (S)-proline methyl ester in presence of $\mathrm{SOCl}_{2}$. In addition, some carbamato-alkyl-naphthol derivatives $^{6,7}$ have been synthetized by condensation of $\beta$ naphthol, aromatic aldehyde and methyl carbamate in ionic liquid media. Other studies indicate that the compound N(2,4-dibromonaphthyl)benzamide was prepared by benzoylation of 2,4-dibromonaphthylamine in pyridine ${ }^{8}$. Additionally, other naphthol derivative [ $\mathrm{N}$-\{3-mercapto-5-(naphthalen-1-yl)$4 H-1,2,4$-triazol-4-yl \}benzamide] was synthesized by the reaction of potassium 2-(2-naphthoyl)hydrazine carbodithioate with $\mathrm{N}$-aminoarylcarboxamides in ethanol to reflux ${ }^{9}$. The compound N-(2-\{[(2-hydroxy-naphtalen-1-yl)-phenyl-methyl]amino -ethyl)-3,4-dinitrobenzamide was synthesized by the reaction of 1-[(2-amino-ethylamino)-phenyl-methyl]naphthalen-2-ol with 3,5-dinitrobenzoic acid using 1-ethyl3-(3-dimethylaminopropyl)-carbodiimide or boric acid as catalys $\mathrm{t}^{10}$. All these experimental results show several procedures that are available for synthesis of naphthol derivatives. Nevertheless, expensive reagents and special conditions are required. Therefore, in this study three naphthol derivatives were synthesized using several chemical strategies.

\section{EXPERIMENTAL}

The compounds 2 (17-(2-amino-ethylimino)-13-methyl$7,8,9,11,12,13,14,15,16,17$-deca-hydro- $6 H$-cyclopenta[a]- 
phenanthren-3-ol), 5 (1-[[(2-aminoethyl)amino]-(phenyl) methyl]-2-naphthol) and 7 (4-allyl-2-methoxyphenyl 4-[(2aminoethyl)amino]-4-oxobutanoate) were prepared according to a reported method ${ }^{10,11}$. The other compounds used in this study were purchased from Sigma-Aldrich Co., Ltd. The melting points for the different compounds were determined on an Electrothermal (900 model). Infrared spectra (IR) were recorded using $\mathrm{KBr}$ pellets on a Perkin Elmer Lambda 40 spectrometer. ${ }^{1} \mathrm{H}$ and ${ }^{13} \mathrm{C}$ NMR spectra were recorded on a Varian VXR-300/5 FT NMR spectrometer at 300 and 75.4 $\mathrm{MHz}$ in $\mathrm{CDCl}_{3}$ using TMS as internal standard. EIMS spectra were obtained with a Finnigan Trace GCPolaris Q. spectrometer. Elementary analysis data were acquired from a Perkin Elmer Ser. II CHNS/0 2400 elemental analyzer.

Synthesis of 3-[[2-(3-hydroxy-13-methyl-6,7,8,9,11, 12,13,14,15,16-decahydro-cyclo- penta[a] phenanthren-17ylideneamino)ethylamino]-(3-hydroxy-naphthalen-2-yl)methyl]-1,7,7-trimethyl-bicyclo[2.2.1] heptan-2-one (4) (Fig. 1): A solution of 1,7,7-trimethylbicyclo[2.2.1] heptan-2-one (1) (50 mg, $0.32 \mathrm{mmol}$ ), compound 2 (100 mg, $0.32 \mathrm{mmol}), 2-$ hydroxy-1-naphthaldehyde (55 mg, $0.32 \mathrm{mmol}$ ) and proline (110.50 mg, $0.96 \mathrm{mmol}$ ) in $10 \mathrm{~mL}$ of methanol was stirring for $72 \mathrm{~h}$ to room temperature. The reaction mixture was evaporated to a smaller volume. After the mixture was diluted with water and extracted with chloroform. The organic phase was evaporated to dryness under reduced pressure, the residue was purified by crystallization from methanol: Water (3:1) yielding $75 \%$ of product, m.p. $98-100{ }^{\circ} \mathrm{C}$; IR (Kbr, $\left.v_{\max }, \mathrm{cm}^{-1}\right): 3410,3338,3320$, $1718 ;{ }^{1} \mathrm{H} \mathrm{NMR}\left(300 \mathrm{MHz}, \mathrm{CDCl}_{3}\right) \delta_{\mathrm{H}}: 0.84(\mathrm{~s}, 6 \mathrm{H}), 0.90(\mathrm{~s}, 3 \mathrm{H})$, 0.96 (s, 3H), 1.24 (m, 1H), 1.38-1.49 (m, 2H), 1.54 (m, 1_H), $1.58-1.62(\mathrm{~m}, 2 \mathrm{H}), 1.70-1.78(\mathrm{~m}, 3 \mathrm{H}), 1.86(\mathrm{~m}, 1 \mathrm{H}), 1.88-2.24$ $(\mathrm{m}, 6 \mathrm{H}), 2.48(\mathrm{~m}, 1 \mathrm{H}), 2.52 .2 .85(\mathrm{~m}, 4 \mathrm{H}), 2.87-3.17(\mathrm{t}, 2 \mathrm{H}, J=$ 6.44), $3.40(\mathrm{t}, 2 \mathrm{H}, J=6.44), 4.26(\mathrm{~m}, 1 \mathrm{H}), 4.79(\mathrm{broad}, 3 \mathrm{H})$, 6.58-6.65 (m, 2H), 7.06-7.43 ( $\mathrm{d}, 2 \mathrm{H}, J=8.10), 7.45(\mathrm{~m}, 2 \mathrm{H})$, 7.50-7.71 (d, $4 \mathrm{H}, J=8.10) \mathrm{ppm} .{ }^{13} \mathrm{C} \mathrm{NMR}\left(75.4 \mathrm{~Hz}, \mathrm{CDCl}_{3}\right) \delta_{\mathrm{C}}$ : 9.35 (C-10), 15.70 (C-44), 19.02 (C-9), 19.34 (C-8), 20.99 (C-3), 21.90 (C-25), 25.78 (C-26), 26.00 (C-22), 27.50 (C-24),

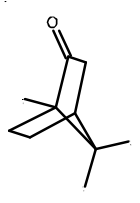

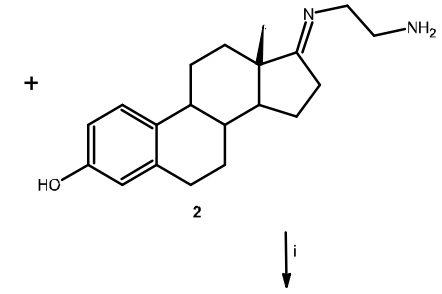

$+$
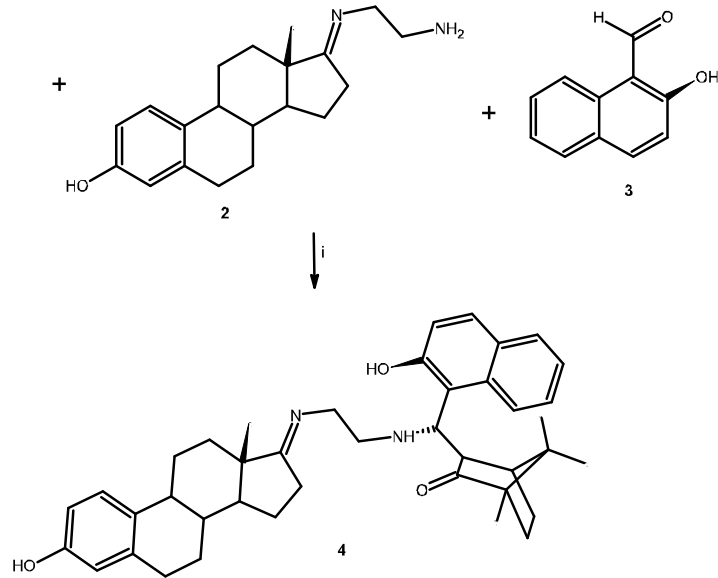

Fig. 1. Synthesis of 3-[[2-(3-hydroxy-13-methyl-6,7,8,9,11,12,13,14,15,16decahydro-cyclopenta[a]phenanthren-17-ylideneamino)ethylamino]-(3-hydroxy-naphthalen-2-yl)-methyl]-1,7,7-trimethylbicyclo[2.2.1]heptan-2-one (4). Reaction of 1,7,7-trimethylbicyclo[2.2.1]heptan-2-one (1) with 17-(2-amino-ethylimino)-13methyl-7,8,9,11,12,13,14,15,16,17-decahydro-6H-cyclopenta[a]phenanthren-3-ol (2) and 2-hydroxy-1-naphthaldehyde (3) to form 4. $\mathrm{i}=$ proline/room temperature
29.00 (C-27), 29.61 (C-4), 32.36 (C-23), 37.60 (C-20), 41.43 (C-18), 43.40 (C-23), 45.09 (C-1), 46.70 (C-14), 50.78 (C-2), 53.23 (C-15), 54.29 (C-19), $55.10(\mathbf{C}-12), 55.66(\mathbf{C}-7), 57.64$ (C-5), 112.60 (C-31), 112.90 (C-42), 114.88 (C-33), 120.27 (C-40), 122.86 (C-36), 123.76 (C-38), 124.98 (C-43), 125.25 (C-34), 125.64 (C-30), 126.40 (C-39), 129.08 (C-37), 130.58 (C-29), 131.90 (C-35), 135.38 (C-28), 150.82 (C-41), 153.96 (C-32), 176.64 (C-17), 219.22 (C-6) ppm. EI-MS m/z: 618.30 $\left(\mathrm{M}^{+} 10\right)$. Anal. calcd. for $\mathrm{C}_{4} 1 \mathrm{H}_{50} \mathrm{~N}_{2} \mathrm{O}_{3}: \mathrm{C}, 79.57 ; \mathrm{H}, 8.14 ; \mathrm{N}$, 4.53. Found: $\mathrm{C}, 79.50 ; \mathrm{H}, 8.10$.

Synthesis of 1-\{phenyl-[2-(1,7,7-trimethyl-bicyclo[2.2.1]hept-2-ylideneamino)ethyl-amino]-methyl $\}$ naphthalen-2-ol (6) (Fig. 2): A solution of 1-[(2-aminoethylamino)-phenyl-methyl]-naphthalen-2-ol (100 mg, 0.34 mmol), 1,7,7-trimethylbicyclo[2.2.1] heptan-2-one (77 mg, $0.50 \mathrm{mmol})$ and boric acid $(50 \mathrm{mg}, 80 \mathrm{mmol})$ in $10 \mathrm{~mL}$ of methanol was stirring for $72 \mathrm{~h}$ to room temperature. The reaction mixture was evaporated to a smaller volume. After the mixture was diluted with water and extracted with chloroform. The organic phase was evaporated to dryness under reduced pressure, the residue was purified by crystallization from methanol: Water (3:1) yielding $60 \%$ of product, m.p. $62-64{ }^{\circ} \mathrm{C}$; IR $(\mathrm{KBr}$, $\left.v_{\max }, \mathrm{cm}^{-1}\right): 3406,3342,3324 ;{ }^{1} \mathrm{H}$ NMR $\left(300 \mathrm{MHz}, \mathrm{CDCl}_{3}\right) \delta_{\mathrm{H}}$ : $0.84(\mathrm{~s}, 3 \mathrm{H}), 0.91(\mathrm{~s}, 3 \mathrm{H}), 0.93(\mathrm{~s}, 3 \mathrm{H}), 1.27-2.58(\mathrm{~m} 7 \mathrm{H})$, 2.97-3.01 (t, 2H, $J=6.44), 3.59(\mathrm{t}, 2 \mathrm{H}, J=6.44), 4.24$ (broad, $2 \mathrm{H}), 5.15(\mathrm{~m}, 1 \mathrm{H}), 6.88(\mathrm{~m}, 2 \mathrm{H}), 7.07(\mathrm{~m}, 1 \mathrm{H}), 7.12(\mathrm{~m}, 2 \mathrm{H})$, $7.27(\mathrm{~m}, 1 \mathrm{H}), 7.41-7.78(\mathrm{~m}, 5 \mathrm{H}) \mathrm{ppm} .{ }^{13} \mathrm{C} \mathrm{NMR}(75.4 \mathrm{~Hz}$, $\left.\mathrm{CDCl}_{3}\right) \delta_{\mathrm{C}}: 11.20(\mathbf{C}-10), 19.02(\mathbf{C}-9), 19.34(\mathbf{C}-8), 27.50(\mathbf{C}-3)$, 31.22 (C-4), 36.16 (C-7), 43.78 (C-2), 47.40 (C-1), 50.60 (C-13), 53.38 (C-12), 55.53 (C-15), 56.34 (C-5), 114.36 (C-18), 121.18 (C-22), 123.57 (C-24), 126.60 (C-23), 127.30 (C-29), 127.90 (C-16), 128.01 (C-20), 128.14 (C-19), 129.20 (C-27, C-31), 129.28 (C-25), 130.20 (C-28, C-30), 138.34 (C-21), 139.30 (C-26), 152.10 (C-17), 180.84 (C-6) ppm. EI-MS m/z: $426.20\left(\mathrm{M}^{+} 10\right)$. Anal. calcd. for $\mathrm{C}_{29} \mathrm{H}_{34} \mathrm{~N}_{2} \mathrm{O}: \mathrm{C}$, 65.00; H, 8.03; N, 6.57. Found: C, 64.98; H, 8.00.
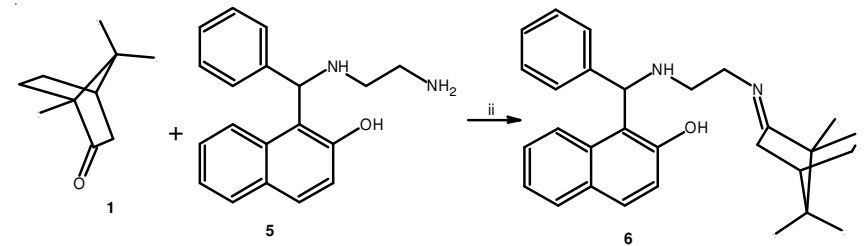

Fig. 2. Synthesis of 1-\{phenyl-[2-(1,7,7-trimethyl-bicyclo[2.2.1]hept-2ylideneamino)ethyl-amino]-methyl \}naphthalen-2-ol (6). Reaction of 1,7,7-trimethylbicyclo[2.2.1]heptan-2-one (1) with 1-[(2-aminoethylamino)-phenyl-methyl]-naphthalen-2-ol (5) to form $\mathbf{6}$. ii = boric acid/room temperature

Synthesis of N-[3-(1-hydroxy-10a,12a-dimethyl2,2,3a,3b,4,5,10,10a,10b,11,12,12a-dodecahydro-1H-7-oxa8-aza-dicyclopenta[a,h]phenanthren-1-ylethynylamino)-3(3-hydroxy-naphthalen-2-yl)-propyl]-succinamic acid 3allyl-5-methoxy-phenyl ester (9) (Fig. 3): A solution of 2hydroxy-1-naphthaldehyde, 4-allyl-2-methoxyphenyl 4-[(2aminoethyl)amino]-4-oxobutanoate and danazol in $10 \mathrm{~mL}$ of ethanol was stirring for $72 \mathrm{~h}$ to room temperature. The reaction mixture was evaporated to a smaller volume. After the mixture was precipitated with water and separated, yielding $70 \%$ of product, m.p. $140{ }^{\circ} \mathrm{C}$; IR $\left(\mathrm{KBr}, v_{\max }, \mathrm{cm}^{-1}\right): 3378,1718,1188$; 
${ }^{1} \mathrm{H}$ NMR $\left(300 \mathrm{MHz}, \mathrm{CDCl}_{3}\right) \delta_{\mathrm{H}}: 0.99(\mathrm{~s}, 3 \mathrm{H}), 1.01(\mathrm{~s}, 3 \mathrm{H})$, $1.03-2.36(\mathrm{~m}, 17 \mathrm{H}), 2.52-2.57(\mathrm{t}, 4 \mathrm{H}), 3.42(\mathrm{t}, 2 \mathrm{H}), 3.46(\mathrm{t}$, $2 \mathrm{H}), 3.52(\mathrm{t}, 2 \mathrm{H}), 4.05(\mathrm{~s}, 3 \mathrm{H}), 5.18-5.95(\mathrm{t}, 2 \mathrm{H}), 6.17(\mathrm{~d}, 1 \mathrm{H})$, 7.1-7.53 (d, 8H), $7.76(\mathrm{~d}, 1 \mathrm{H}), 8.00$ (broad, 3H), $8.10(\mathrm{~d}, 1 \mathrm{H})$ ppm. ${ }^{13} \mathrm{C}$ NMR $\left(75.4 \mathrm{~Hz}, \mathrm{CDCl}_{3}\right) \delta_{\mathrm{C}}: 12.80(\mathbf{C}-22), 19.44$ (C-21), 21.10 (C-19), 22.94 (C-13), 29.50 (C-43), 31.35 (C-17), 31.69 (C-18), $31.92(\mathbf{C}-42), 33.02(\mathbf{C}-20), 33.64(\mathbf{C}-5)$, 35.95 (C-6), 37.03 (C-20), 38.73 (C-12), 39.92 (C-56), 43.56 (C-28), 47.40 (C-10), 52.88 (C-7), 53.15 (C-9), 55.85 (C-55), 58.46 (C-27), 67.26 (C-24), 81.13 (C-11), 86.34 (C-25), 110.50 (C-15), 113.08 (C-48), 113.46 (C-34), 116.01 (C-58), 119.69 (C-38), 121.44 (C-4), 121.66 (C-51), 122.79 (C-50), 123.21 (C-40), 123.83 (C-35), 125.61 (C-39), $128.70(\mathbf{C}-41)$, 130.30 (C-36), 133.57 (C-37), 134.42 (C-32), 137.56 (C-57), 139.12 (C-49), 139.20 (C-46), 141.56 (C-16), 142.01 (C-33), 149.58 (C-3), 151.30 (C-47), 156.04 (C-14), 168.64 (C-44), 169.68 (C-30) ppm. EI-MS m/z: $783.36\left(\mathrm{M}^{+} 10\right)$. Anal. calcd. for $\mathrm{C}_{48} \mathrm{H}_{53} \mathrm{~N}_{3} \mathrm{O}_{7}$ : C, 73.54; H, 6.81; N, 5.36. Found: C, 73.50; $\mathrm{H}, 6.80$.

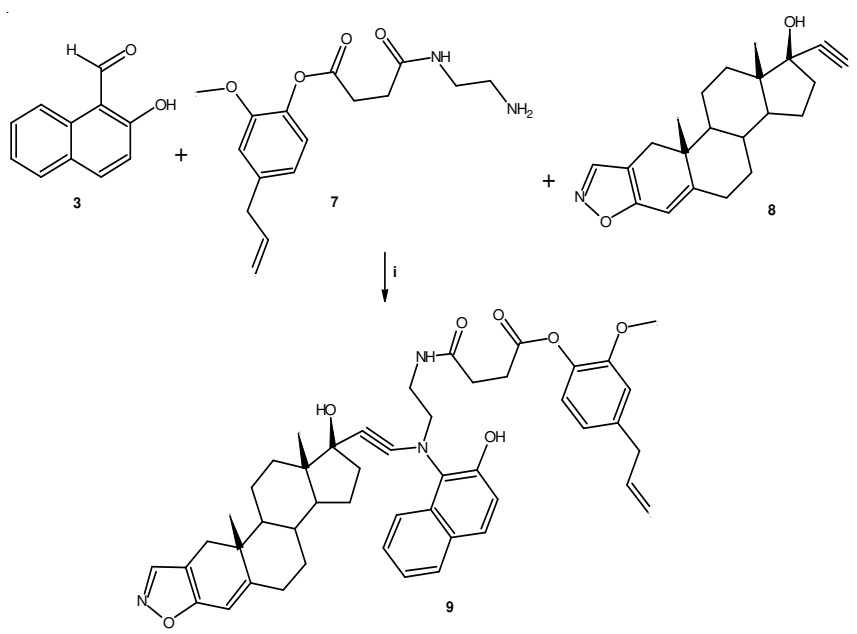

Fig. 3. Synthesis of N-[3-(1-hydroxy-10a,12a-dimethyl-2,2,3a,3b,4,5,10, 10a, 10b, 11,12,12a-dodecahydro-1H-7-oxa-8-aza-dicyclopenta[a,h]phenanthren-1-ylethynylamino)-3-(3-hydroxy-naphthalen-2yl)-propyl]-succinamic acid 3-allyl-5-methoxy-phenyl ester (9). Reaction of 2-hydroxy-1-naphthaldehyde (3), 4-Allyl-2-methoxyphenyl 4-[(2-aminoethyl)amino]-4-oxobutanoate (7) and danazol (8) to form 9. iii = Ethanol/room temperature

\section{RESULTS AND DISCUSSION}

Several strategies are available for enantioselective catalysis, including heterogeneous catalysis ${ }^{12-14}$. For example, proline is used as catalyst in asymmetric reactions (three components system) from ketones, aldehydes and amines ${ }^{15,16}$. Therefore, in this study we report a straight forward route for synthesis of 3-[[2-(3-hydroxy-13-methyl-6,7,8,9,11,12,13,14, 15,16-decahydro-cyclopenta[a]phenanthren-17-ylideneamino)-ethylamino]-(3-hydroxy-naphtalen-2-yl)-methyl]1,7,7-trimethyl-bicyclo[2.2.1] heptan-2-one (4) by the reaction of 1,7,7-trimethylbicyclo[2.2.1] heptan-2-one with 17-(2amino-ethylimino)-13-methyl-7,8,9,11,12,13,14,15,16,17decahydro- $6 H$-cyclopenta[a]phenanthren-3-ol and 2-hydroxy1-naphthaldehyde using proline as catalyst. The ${ }^{1} \mathrm{H}$ NMR spectrum of 4 shows signals at 0.84 and 0.90 ppm for methyl groups bound to bicyclic ring; at $0.96 \mathrm{ppm}$ for methyl group bound to steroid nucleus; at 1.24, 1.54, 1.70-1.78, 1.88-2.24,
2.52-2.85, 6.58-6.65 and 7.45 ppm for steroid nucleus; at 1.38$1.49,1.58-1.62,1.86$ and $2.48 \mathrm{ppm}$ for protons involved in the bicyclic ring; at 2.87-3.17 and $3.40 \mathrm{ppm}$ for arm bound to both imino and amino groups; at $4.26 \mathrm{ppm}$ for methylene bound to both phenyl and amino groups; at $4.79 \mathrm{ppm}$ for both amino and hydroxyl groups; at 7.06-7.71 ppm for phenyl groups.

On the other hand, the ${ }^{13} \mathrm{C}$ NMR spectrum of compound 4 contains peaks at 9.35, 19.02 and 19.34 ppm for methyl groups bound to bicyclic ring; at $15.70 \mathrm{ppm}$ for methyl group of steroid fragment; at 20.99, 29.61, 45.09, 50.78, 55.10, 55.66 and $219.22 \mathrm{ppm}$ for protons involved in the bicyclic ring; at 21.90, 25.78, 26.00, 27.50, 29.00, 32.36, 37.60, 41.43, 43.40, $54.29,112.60,114.88,125.64,130.58,135.38153 .32$ and $176.64 \mathrm{ppm}$ for steroid nucleus; at 46.70 and $53.23 \mathrm{ppm}$ for arm bound to both imino and amino groups; $55.10 \mathrm{ppm}$ for carbon bound to amino, phenyl and bicyclic ring; at 112.90, $120.27,122.86-125.25,126.40-129.08,131.90$ and 150.82 ppm for phenyl groups. Finally, the presence of compound 4 was further confirmed from mass spectrum which showed a molecular ion at $m / z 618.30$.

The second stage was achieved by the synthesis of 1\{phenyl-[2-(1,7,7-trimethyl-bicyclo[2.2.1]hept-2-ylideneamino)ethyl-amino]-methyl \}naphthalen-2-ol (6); this compound has in the chemical structure an imino group. It is importantto mention that there are several procedures for thesynthesis of imines which are described in the literature ${ }^{10,17}$. For example, the synthesis of imines by the reaction of benzaldehyde derivative with benzene-1,2-diamine using boric acid as catalyst ${ }^{18}$. Therefore, in this study the compound $\mathbf{6}$ was developed by the reaction of 1-[(2-amino-ethylamino)-phenylmethyl]-naphthalen-2-ol and 1,7,7-trimethyl-bicycle[2.2.1] heptan-2-one using boric as catalyst to form an imino group involved in the compound $\mathbf{6}$. The ${ }^{1} \mathrm{H}$ NMR spectrum of 6 shows signals at $0.84,0.91$ and 0.93 ppm for methyl groups bound to bicyclic ring; at 1.27-2.58 ppm for protons involved in the bicyclic ring; $2.97-3.01$ and $3.59 \mathrm{ppm}$ for methylene groups bound to both imino and amino groups; at $4.29 \mathrm{ppm}$ for both amino and hydroxyl groups; at $5.15 \mathrm{ppm}$ for methylene group bound to both amino and phenyl groups; at 6.88-7.78 ppm for phenyl groups. The ${ }^{13} \mathrm{C}$ NMR spectrum of 6 contains peaks at 11.20, 19.02, $19.34 \mathrm{ppm}$ for methyl groups bound to bicyclic ring; at 27.50, 31.22, 36.16, 43.78, 47.40, 56.34 and 180.84 ppm for protons involved in the bicyclic ring; at 55.53 ppm for methylene group bound to both amino group and phenyl groups; at 50.60 and 53.38 ppm for methylene groups bound to imino and amino groups; at 114.36-152.10 ppm for phenyl groups. Finally,the presence of compound $\mathbf{6}$ was further confirmed from mass spectrum which showed a molecular ion at $m / z, 426.20$.

The third stage was achieved by the synthesis of compound 9 using the three components(2-hydroxy-1-naphthaldehyde, 4allyl-2-methoxyphenyl 4-[(2-aminoethyl) amino]-4-oxobutanoate and danazol). It is important to mention, that there are many procedures which have been used with this method in order to synthesize several compounds. The most widely practiced method employs boric acid ${ }^{19}$, silica sulfuric acid ${ }^{20}$, poly(4-vinylpyridinecodivynylbenzene)-Cu(II)complex ${ }^{21}, \mathrm{H}_{2} \mathrm{SO}_{4}{ }^{22}$, silica triflate ${ }^{23}$ and phosphorus pentoxide ${ }^{24}$. Nevertheless, despite its wide scope, the former protocols suffer from several drawbacks e.g., some 
reagents have a limited stability and its preparation can be dangerous. Analyzing these data, in this study a straight forward route is reported for the synthesis of 9 . The ${ }^{1} \mathrm{H}$ NMR spectrum of 9 shows signals at 0.99 and $1.01 \mathrm{ppm}$ for methyl groups bound to steroid nucleus; at 1.03-2.52, 6.17 and $7.76 \mathrm{ppm}$ for steroid nucleus; at 2.52-2.57 ppm for methylene groups bound to both amide and ester groups; at 3.42-3.46 ppm for methylene group bound to both amino groups; $3.52 \mathrm{ppm}$ for methylene group bound to phenyl group; at 4.05 for methoxy group; 5.18$5.95 \mathrm{ppm}$ for protons of alkene group; at 7.10-7.53 and 8.10 ppm for phenyl groups. Finally, other signal at $8.00 \mathrm{ppm}$ for amino and hydroxyl groups were found.

On the other hand, the ${ }^{13} \mathrm{C}$ NMR spectrum of 9 contains peaks at 12.80 and $19.44 \mathrm{ppm}$ for methyl groups bound to steroid nucleus; at 21.10, 22.94, 31.35-31.69, 33.02-38.73, $47.40-53.15,81.13,110.50,121.44,141.56$ and $149.58-156.04$ ppm for steroid nucleus; at 29.50 and 31.92 ppm for carbons bound to both ester and amide groups; at $39.92 \mathrm{ppm}$ for methylene group bound to phenyl group; at 43.56 and 58.46 ppm for carbons bound to amino groups; at $55.85 \mathrm{ppm}$ for methoxy group; at 67.26 and 86.34 ppm for alkyne group; at 113.08-113.46, 119.69, 121.66-134.42, 139.12-139.20 and $142.01 \mathrm{ppm}$ for phenyl groups; at 116.01 and $137.56 \mathrm{ppm}$ for alkene group. Finally, other signals at $168.64 \mathrm{ppm}$ for ester group; at $169.68 \mathrm{ppm}$ for amide group. In addition, the presence of 9 was further confirmed from mass spectrum which showed a molecular ion at $m / z 783.36$.

\section{REFERENCES}

1. H. Kusama, H. Funami, J. Takaya and N. Iwasawa, Org. Lett., 6, 605 (2004).

2. J. Cochran and A. Padwa, Tetrahedron Lett., 36, 3495 (1995).
3. H. Reza, A. Hosseinian and M. Ghashang, Tetrahedron Lett., 49, 5804 (2008).

4. H. House, D.G. Koepsell and W.J. Campbell, J. Org. Chem., 37, 1003 (1972).

5. Z. Xin, C. Da, S. Dong, D. Liu, J. Wei and R. Wang, Tetrahedron Asymm., 13, 1937 (2002).

6. M. Dabiri, A. Delbari and A. Bazgir, Heterocycles, 71, 543 (2007).

7. B. In-Soo, K. Yoo-Shin and P. Yong-Tae, Bull. Korean Chem. Soc., 24, 916 (2003)

8. N. Desai, P. Shihora, K. Rajpara, V. Joshi, H. Vaghani, H. Satodiya and A. Dodiya, Med. Chem. Res., 21, 2981 (2012).

9. N. Pradidphol, N. Kongkathip, P. Sittikul, N. Boonyalai and B. Kongkathip, Eur. J. Med. Chem., 49, 253 (2012).

10. L. Figueroa-Valverde, F. Díaz-Cedillo, E. García-Cervera and E. PoolGómez, Oriental J. Chem., 28, 1085 (2012).

11. L. Figueroa-Valverde, F. Díaz-Cedillo, E. García-Cervera, E. PoolGómez and M. López-Ramos, Bulgarian Chem. Commun., 45, 71 (2013).

12. D.A. Evans, K.A. Woerpel, M.M. Hinman and M.M. Faul, J. Am. Chem. Soc., 113, 726 (1991).

13. K. Narasaka, Synthesis, 1 (1991).

14. H. Ishitani and S. Kobayashi, Tetrahedron Lett., 37, 7357 (1996).

15. H. Martin, M.-L. Tsao, C.M. Hadad and M.S. Platz, J. Am. Chem. Soc., 124, 7226 (2002).

16. S. Kobayashi, M. Moriwaki and I. Hachiya, Tetrahedron Lett., 37, 2053 (1996).

17. H.R. Shaterian, A. Hosseinian and M. Ghashang, Tetrahedron Lett., 49, 5804 (2008).

18. M. Hania, E-J. Chem., 6, 629 (2009).

19. S. Tu, F. Fang, C. Miao, H. Jiang, Y. Feng, D. Shi and X. Wang, Tetrahedron Lett., 44, 6153 (2003).

20. P. Salehi, M. Dabiri, M.A. Zolfigol and M.A. Bodaghi Fard, Tetrahedron Lett., 44, 2889 (2003).

21. R. Yarapathi, S. Kurva and S. Tammishetti, Catal. Commun., 5, 511 (2004).

22. J. Bussolari and P. McDonnell, J. Org. Chem., 65, 6777 (2000).

23. F. Shirini, K. Marjani and H. Nahzomi, ARKIVOC, 51 (2007).

24. R. Crossland and K. Servis, J. Org. Chem., 35, 3195 (1970). 